RESEARCH REPORT

\title{
Association between childhood fatal injuries and socioeconomic position at individual and area levels: a multilevel study
}

\author{
Myoung-Hee Kim, S V Subramanian, Ichiro Kawachi, Chang-Yup Kim
}

J Epidemiol Community Health 2007;61:135-140. doi: 10.1136/jech.2006.047738

See end of article for authors' affiliations

......................

Correspondence to: Dr C-Y Kim, Seoul National University School of Public Health, 28 Yongon-dong, Chongno-gu, Seoul 110799, South Korea; cykim@snu.ac.kr

Accepted 5 June 2006

\begin{abstract}
Objectives: To simultaneously examine the effects of area-level and individual-level socioeconomic position on fatal injuries in children $<5$ years of age.

Methods: A retrospective cohort study based on the national birth and death registers of Korea. 2667060 children born during 1995-8 were followed up from birth to the 5th birthday. Cumulative incidences of fatal injuries were calculated, and through multilevel Poisson regression models, relative risks (RRs) of incidence rate were estimated according to children's sex, father's occupation and mother's education at individual level, and deprivation and degree of urbanity at area level.

Results: Girls had lower risk for fatal injuries than boys (RR $0.81 ; 95 \%$ confidence interval (CI) 0.75 to 0.87 ). Compared with children with fathers in non-manual occupations, those with fathers in manual (RR 1.45; 95\% $\mathrm{Cl} 1.34$ to 1.58 ) or other occupations (RR 1.35; $95 \% \mathrm{Cl} 1.13$ to 1.62) had higher risk. Children with mothers who were high school graduates (RR $1.23 ; 95 \% \mathrm{Cl} 1.12$ to 1.36 ) or junior school graduates (RR $1.91 ; 95 \% \mathrm{Cl}$ 1.66 to 2.19 ) had higher risk than those whose mothers were college graduates. After controlling for individual-level variables, residence in more deprived districts (RR 1.13; 95\% Cl 1.05 to 1.21 ) or nonmetropolitan regions (urban RR $1.34 ; 95 \% \mathrm{Cl} 1.22$ to 1.47 and rural RR $1.61 ; 95 \% \mathrm{Cl} 1.40$ to 1.86 ) was significantly associated with increased risk.

Conclusions: Both individual-level and area-level socioeconomic position influenced the risk for childhood fatal injuries. To reduce the socioeconomic inequalities and the absolute burden in Korea, universal strategies should receive priority, and special efforts in implementation should be directed towards both disadvantaged households and areas.
\end{abstract}

njury is a leading cause of morbidity and mortality among children in developing as well as in developed countries. ${ }^{1}$ As a result of effective social interventions and increased awareness, however, mortality in children from injury has been continuously declining for decades in many developed countries. $^{2-4}$ Injury is not a random event, and like many other health problems, is more concentrated among socioeconomically disadvantaged groups. On the basis of their thorough review, Cubbin and Smith ${ }^{5}$ reported that the consistent inverse relationship between socioeconomic position (SEP) and fatal unintentional injuries was found across all age groups, regardless of the SEP measures used.5 In particular, they pointed out that area-level characteristics (eg, neighbourhood deprivation) as well as individual-level SEP may influence the risk for morbidity and mortality from injury.

Why do places matter for injury risk? One reason is that different socioeconomic groups face different hazards within their social contexts. For young children, environmental factors are especially important as their ability to control their surroundings is quite limited. Recent studies using multilevel analysis found that both individual-level and area-level factors influence childhood injury. ${ }^{6-10}$ However, those multilevel studies have been limited in several respects. Firstly, although various individual-level variables, including children's age or sex or maternal age or education, ${ }^{68-10}$ or a survey respondent's information, ${ }^{7}$ were used across studies, they could not properly reflect the SEP of household, which could cause insufficient control for compositional confounding. Secondly, only morbidity from injury was examined through collection of hospital records or self-reports, so bias due to healthcare access or subjective reporting could not be ruled out. Thirdly, all the above-mentioned studies were conducted in Western industrialised societies, and the evidence for socioeconomic inequalities in childhood injury is scarce in emerging economies or developing countries.

Our study has three distinctive features, firstly, we sought to simultaneously identify the effects of area-level as well as individual-level SEP on fatal childhood injury through detailed measurement at both levels. Secondly, mortality from injury is used as an outcome from the nationally representative sample. Finally, it is the first multilevel study about childhood injuries conducted in a non-Western industrialised setting-namely, in South Korea (hereafter Korea), an example of an emerging economy with the highest rank in childhood fatal injuries during 1991-5 among Organization for Economic Co-operation and Development countries. ${ }^{11}$

\section{METHODS}

\section{Sources of data}

Data were obtained from three different sources: (1) the National Birth Registration database (NBR) between 1995 and 1998; (2) the National Death Registration database (NDR) between 1995 and 2002; and (3) the National Census in 1995.

From the NBR, we obtained the records of 2791962 live births between 1995 and 1998 nationally, and through the personal identification numbers (PINs), they were linked to the NDR for the subsequent 5 years (from birth to the 5 th birthday) by the staff of the National Statistical Office. A total of 4698

Abbreviations: NBR, National Birth Registration database; NDR, National Death Registration database; PINs, personal identification numbers; SEP, socioeconomic position 
duplicated records were found, with 256 redundant PINs, which may have resulted from incomplete PINs due to administrative problems in the birth registration process. These duplicates were excluded from analysis. Next, a series of information was abstracted: birth date, sex of newborn, residential address (district), occupation and educational attainment of father and mother. Among children born between 1995 and 1998, a total of 12255 deaths were identified during the 5-year follow-up period. For the causes of death, the NDR adopted the 10th revision of the International Classification of Disease. A recent Korean study reported that the overall proportion of 1990-2002 deaths <10 years of age certified by doctors was $>90 \%$, with continuous increases across successive years, and the cases of external cause were more likely to be diagnosed by doctors. ${ }^{12}$ We defined fatal injuries when the child died from external cause with one of the following codes: " $\mathrm{V}$ ", " $\mathrm{W}$ ", " $\mathrm{X}$ ", or " $\mathrm{Y}{ }^{1}{ }^{13}$ Excluding the records with missing values in socioeconomic variables and cause of death, we analysed the records for 2667060 children (95.7\% of the initial data) and 2926 deaths from injuries $(23.9 \%$ of total deaths), including 1214 deaths from transportationrelated causes, 611 from suffocation, 367 from fall and 324 from drowning.

For individual-level SEP measures, we used mother's education and father's occupation from the NBR. ${ }^{3}{ }^{14}{ }^{15}$ Father's occupation was categorised into three groups: (1) non-manual (legislator or administrator, professional, engineer and clerk); (2) manual (service or sales worker, farmer or fisher, skilled labourer, operator and unskilled labourer); and (3) others (unemployed, economically inactive or unknown). Mother's education was classified as (1) college graduate or above, (2) high school graduate, or (3) junior high school graduate or below. In a preliminary analysis, we examined the effect of father's education instead of father's occupation, and found a gradient as observed for mother's education. However, the models including father's occupation were found to explain more of the area-level variation than models with father's education, and even when both variables were simultaneously included in a model, the results changed little. This may be owing to the fact that the study subjects were relatively well educated $(91.8 \%$ graduated from high school or above) and so the education level was less sensitive to differences in social status.

Considering that both material and informational resources are important for childhood safety, informational resources could be represented by the education level of the mother who is usually a caregiver in Korea, whereas material resources could be better captured by the father's occupation.

We used districts as the spatial unit of analysis, which is administratively defined in Korea and has a relatively large and heterogeneous population, ranging from 12000 to 630000 . The district is the smallest municipal unit capable of autonomous policy implementation in Korea and is also the lowest statistical unit for which official data are available. For area-level SEP measures, degree of urbanity, ${ }^{16-19}$ which is designated by the government (metropolitan, urban and rural), and a deprivation index ${ }^{62021}$ were assigned to 247 districts across the country. The deprivation index was made through modification of the Townsend and Carstairs index..$^{22}$ On the basis of the National Census data in 1995, we calculated the district-specific proportions of households: living in apartments; without a car; in a crowded condition ( $>1.5$ persons/room); with a female head; in tenancy; and under substandard living conditions (without hot-water supply, a flush toilet or a modern kitchen). In addition, the following district-specific proportions of individuals were calculated: high school graduate or above among adults $>25$ years of age; unemployed among economically active men; in manual occupations among employed men; $>65$ years of age, a higher proportion of which could indicate a high level of poverty in Korea where senior pensions are not sufficient for the elderly who lack other sources of income. ${ }^{23}$ All proportions were $\mathrm{z}$ standardised, and a factor analysis with varimax rotation was carried out, which showed that home ownership and unemployment rate belonged to a factor different from the others. This might come from the characteristics of rural region, where the residents are likely to own houses with low market value, and the unemployment rate is relatively low owing to the existence of subsistence farming. Finally, we constructed the district-specific deprivation index by averaging the z-standardised scores of eight proportions (household not living in apartments; without a car; in a crowded condition; with a female head; and under substandard living conditions, and individuals with below high school graduation among adults $>25$ years of age, $>65$ years of age and in manual occupations among employed men), and linked it to the NBR based on the residential address. A positive, larger score means higher levels of deprivation. Deprivation indices developed in Western countries may not be transferable to the Asian context. A Japanese study found differences in associations with health between an index that included municipal-level unemployment and overcrowding, compared with an index that included education and per capita income. ${ }^{24}$ In this study, we used one composite index of deprivation, excluding unemployment rate and home ownership, but adding the variable "degree of urbanity" instead of creating another composite index.

\section{Statistical analysis}

To improve mathematical efficiency while securing individuallevel information, we constructed a new dataset in an aggregated format, with a hierarchical multilevel structure. ${ }^{25} 26$ Through cross tabulation by individual-level predictors (child's sex, father's occupation and mother's education), from about 2.6 million records, we obtained a total of 4438 cells at level 1 within 247 districts at level 2.

The response variable, the number of deaths in each cell, was modelled with the offset, the expected death count derived from person-time accounts. Estimates were obtained from multilevel Poisson regression models with log link function, using the penalised quasi-likelihood, second-order approximation procedure. ${ }^{27}$ We fitted the models through the statistical software MLwiN V.2 (Institute of Education, London, UK), which uses the iterative generalised least squares algorithm. ${ }^{28}$

We examined a series of models from simple to complex by adding individual-level and area-level predictors, and intra-level and cross-level interaction terms, through which we could evaluate the relationship between fatal injuries and individuallevel SEP (fixed parameters) conditional on area-level variations (random parameters). In addition, the degree to which district deprivation and urbanisation could explain the mortality variation across districts (fixed parameters) was examined.

\section{RESULTS}

For a total of 2667060 births and 13104907 person-years, 2926 fatal injuries were identified (cumulative incidence 1.1/ 1000 children; incidence rate 22/100 000 person-years). As for injury mechanism, transport-related cause $(0.46 / 1000)$ was the most common, followed by suffocation (0.23), falls $(0.14)$ and drowning (0.12; data not shown). The size of birth cohorts decreased as time passed, from 698889 to 628224 , and the rates decreased from 1.3 to $0.9 / 1000$ across successive birth cohorts. Within every cohort, mortality was higher in boys than in girls (table 1 ).

Comparing the cumulative incidence of fatal injuries between socioeconomic groups, it was higher in children born from 
Table 1 Cumulative incidence of fatal injuries among children $<5$ years by birth year and sex

\begin{tabular}{|c|c|c|c|c|c|c|c|c|c|}
\hline \multirow[b]{2}{*}{$\begin{array}{l}\text { Birth } \\
\text { year }\end{array}$} & \multicolumn{3}{|l|}{ Boy } & \multicolumn{3}{|l|}{ Girl } & \multicolumn{3}{|l|}{ Total } \\
\hline & Cohort & Death* & $\begin{array}{l}\text { Mortality } \\
\text { (/1000) }\end{array}$ & Cohort & Death* & $\begin{array}{l}\text { Mortality } \\
\text { (/1000) }\end{array}$ & Cohort & Death* & $\begin{array}{l}\text { Mortality } \\
\text { (/1000) }\end{array}$ \\
\hline 1995 & 371469 & 517 & 1.4 & 327420 & 373 & 1.1 & 698889 & 890 & 1.3 \\
\hline 1996 & 357374 & 448 & 1.3 & 320048 & 331 & 1 & 677422 & 779 & 1.1 \\
\hline 1997 & 344643 & 377 & 1.1 & 317882 & 297 & 0.9 & 662525 & 674 & 1 \\
\hline 1998 & 329045 & 351 & 1.1 & 299179 & 232 & 0.8 & 628224 & 583 & 0.9 \\
\hline Total & 1402531 & 1693 & 1.2 & 1264529 & 1233 & 1 & 2667060 & 2926 & 1.1 \\
\hline
\end{tabular}

*Number of fatal injuries occurred from birth to 5th birthday.

fathers in manual occupations $(1.4 / 1000)$ or others $(1.2 / 1000)$ than in those born from fathers in non-manual occupations (0.8/1000). Mother's education also showed similar effects; children born from mothers with more education had lower fatal injury rates. As for area level, metropolitan regions had the lowest rate $(0.8 / 1000)$, less than a half of the rates in the rural region (1.8/1000). In addition, the more deprived the districts, the higher the fatal injury rates. These findings were observed in both boys and girls (table 2 ).

Figure 1 shows the association between fatal injury rates and area characteristics, in which the circle size is proportional to the population size. Overall, we observed that non-metropolitan regions were more likely to be deprived, and more deprived districts had higher mortality with more variability.

Table 3 shows fixed and random parameters estimated from multilevel Poisson regression models. Significant variation was seen in mortality across districts (model 1 ). When individuallevel variables were added (model 2), all of them (child's sex, father's occupation and mother's education) were statistically significant and random variation between districts decreased by $36 \%$, which meant that about one third of the area-level variation came from differences in the population composition in each district. When the district deprivation variable was added (model 3), the between-districts variation decreased by an additional 25.4\%, and the effects of individual-level variables were attenuated. By adding the urbanity variable (model 4), we observed further reduction in the betweendistricts variation (additional 26.3\%) and risk attenuation for district deprivation. As for intralevel interaction, there was no significant interaction between father's occupation and mother's education, or between deprivation and urbanity (data not shown). However, we found a significant cross-level interaction; district deprivation had a greater effect on fatal injuries among the children whose parents were from lower SEP strata (model 5 and 6). The between-districts variation became insignificant when both the degree of urbanity and deprivation index were included in the models (table 3).

For common types of injury, including transportation-related causes, suffocation, falls and drowning, we estimated the effects of urbanisation and deprivation, controlling for individual-level variables. Compared with metropolitan regions, rural areas had higher risk for all types of injury. Deprivation showed a clear positive relationship with mortality by transportationrelated causes and drowning (fig 2).

\section{DISCUSSION}

From multilevel Poisson regression models, we found that male sex of child, lower occupational class of father and lower education of mother were significantly associated with increased risk for fatal injuries among children $<5$ years. In addition, residence in more deprived districts or non-metropolitan regions was associated with higher risk even after controlling for individual-level variables.

\section{Methodological issues}

Our study has several strengths from a methodological perspective. Firstly, this analysis was based on nationwide

Table 2 Cumulative incidence of fatal injuries (per 1000) (95\% Cl) among children $<5$ years by SEP

\begin{tabular}{|c|c|c|c|}
\hline Variables & Boy & Girl & Total \\
\hline \multicolumn{4}{|l|}{$\begin{array}{l}\text { Individual level } \\
\text { Father's occupation }\end{array}$} \\
\hline Non-manual & $0.9(0.8$ to 1.0$)$ & $0.7(0.6$ to 0.8$)$ & $0.8(0.8$ to 0.8$)$ \\
\hline Manual & 1.5 (1.4 to 1.6$)$ & $1.3(1.2$ to 1.4$)$ & $1.4(1.3$ to 1.5$)$ \\
\hline Others & $1.4(1.1$ to 1.8$)$ & $1.0(0.8$ to 1.3$)$ & $1.2(1.0$ to 1.4$)$ \\
\hline \multicolumn{4}{|l|}{ Mother's education } \\
\hline College & $0.8(0.7$ to 0.9$)$ & $0.7(0.6$ to 0.8$)$ & $0.8(0.7$ to 0.9$)$ \\
\hline High school & $1.3(1.2$ to 1.4$)$ & $1.0(0.9$ to 1.1$)$ & 1.1 (1.1 to 1.2 ) \\
\hline Junior high school & 2.1 (1.8 to 2.4$)$ & $1.9(1.6$ to 2.2$)$ & 2.0 (1.8 to 2.2$)$ \\
\hline \multicolumn{4}{|l|}{$\begin{array}{l}\text { Area-level } \\
\text { Urbanity }\end{array}$} \\
\hline Metropolitan & $0.9(0.8$ to 1.0$)$ & $0.8(0.7$ to 0.9$)$ & $0.8(0.8$ to 0.9$)$ \\
\hline Urban & $1.3(1.2$ to 1.4$)$ & $1.0(0.9$ to 1.1$)$ & $1.2(1.1$ to 1.3$)$ \\
\hline Rural & 2.1 (1.9 to 2.3$)$ & $1.4(1.2$ to 1.6$)$ & 1.8 (1.7 to 2.0 ) \\
\hline \multicolumn{4}{|l|}{ Deprivation } \\
\hline 1st (least) & $1.0(0.9$ to 1.1$)$ & $0.9(0.8$ to 1.0$)$ & $0.9(0.8$ to 1.0$)$ \\
\hline 2nd & 1.1 (1 to 1.2 ) & $0.9(0.8$ to 1.0$)$ & $1.0(0.9$ to 1.1$)$ \\
\hline $3 \mathrm{rd}$ & $1.3(1.2$ to 1.5$)$ & 1.1 (1.0 to 1.2$)$ & $1.2(1.1$ to 1.3$)$ \\
\hline 4th & $1.8(1.6$ to 2.1$)$ & 1.5 (1.3 to 1.8$)$ & 1.6 (1.4 to 1.8$)$ \\
\hline 5th (most) & $2.3(1.0$ to 2.7$)$ & $1.5(1.2$ to 1.9$)$ & 1.9 (1.7 to 2.2$)$ \\
\hline
\end{tabular}




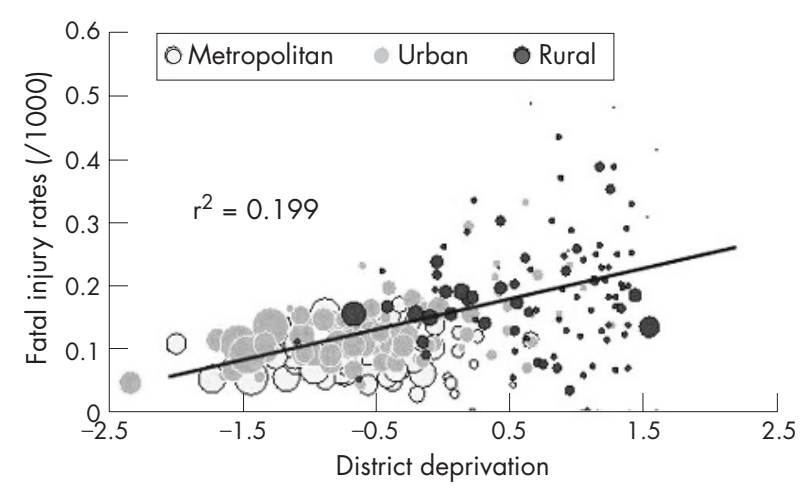

Figure 1 Cumulative incidence of fatal injuries among children $<5$ years according to district deprivation.

birth cohorts, ensuring a large sample size and representativeness. Secondly, our outcome was identified through retrospective follow-up. As the exposure had been measured before the outcome, we could avoid the possibility of reverse causation that childhood fatal injuries resulted in the downward mobility of the affected households. Thirdly, although previous multilevel studies used demographic variables such as maternal age or marital status as a proxy for individual-level SEP, ${ }^{6-8}$ we used direct measures, both father's occupation and mother's education. Finally, we adopted multilevel models, through which we could simultaneously examine the effects of individual-level and area-level SEP and explore to what extent the fixed parameters explained the area-level variation in fatal injuries. ${ }^{29}$ In addition, on the basis of subanalysis, we could examine types of injury in relation to area.

However, our study has some limitations. Firstly, we included only data without missing values on SEP variables. However, when comparing the fatal injury rates between the excluded group and the study subjects, we did not find significant differences (fatal injury rates 1.0 and 1.1/1000 children, respectively, $\mathrm{p}=0.75$ ). Secondly, although we found socioeconomic inequalities in injury mortalities, we could not identify whether they resulted from higher incidence of injuries, or lower survival due to worse severity or inappropriate healthcare access. Previous studies showed that incidence in itself was high, and injuries by fatal mechanism were more common in lower SEP groups, ${ }^{20}{ }^{30}$ but further studies analysing incident cases and subsequent management are warranted. Thirdly, although we more thoroughly measured the individual-level SEP compared with previous studies, the possibility of residual confounding arising from another aspects such as income or assets, could not be completely ruled out. Fourthly, we used the area information for the districts where the child was born, and therefore the place of injury was not necessarily the same as that of birth. However, the consistent gaps observed across areas strongly suggested the influence of the SEP at area-level. In addition, our study differs from previous studies of contextual variations in injury,,$^{6-81031}$ which have tended to use smaller spatial units of aggregation (eg, neighbourhoods and wards). The causal processes underlying area variations in injury are likely to differ according to the spatial scale of analysis. Thus, neighbourhood variations in injury have been linked to local differences in traffic patterns, as well as supervision of children and play activity. As our study examined variations in injury across larger spatial scales (districts), we were unable to consider these local causal processes. Nonetheless, our findings have value for planning purposes by pointing out area-based socioeconomic disparities in injury mortality rates across larger geographical scales.

Finally, although we identified the area differentials in some common types of injury, there are points to be explored further; for instance, among transportation-related injuries, traffic design and physical environment at area level would be more important for pedestrian, whereas safety device or regulations throughout the country would be so for passengers. However, we could not obtain such detailed information on subtypes of injury. For more elaborate interventions at individual and area levels, further studies on specific types of injury should be followed up, based on updated mortality data.

Table 3 Parameter estimates from multilevel Poisson regression models (RR, 95\% CI)

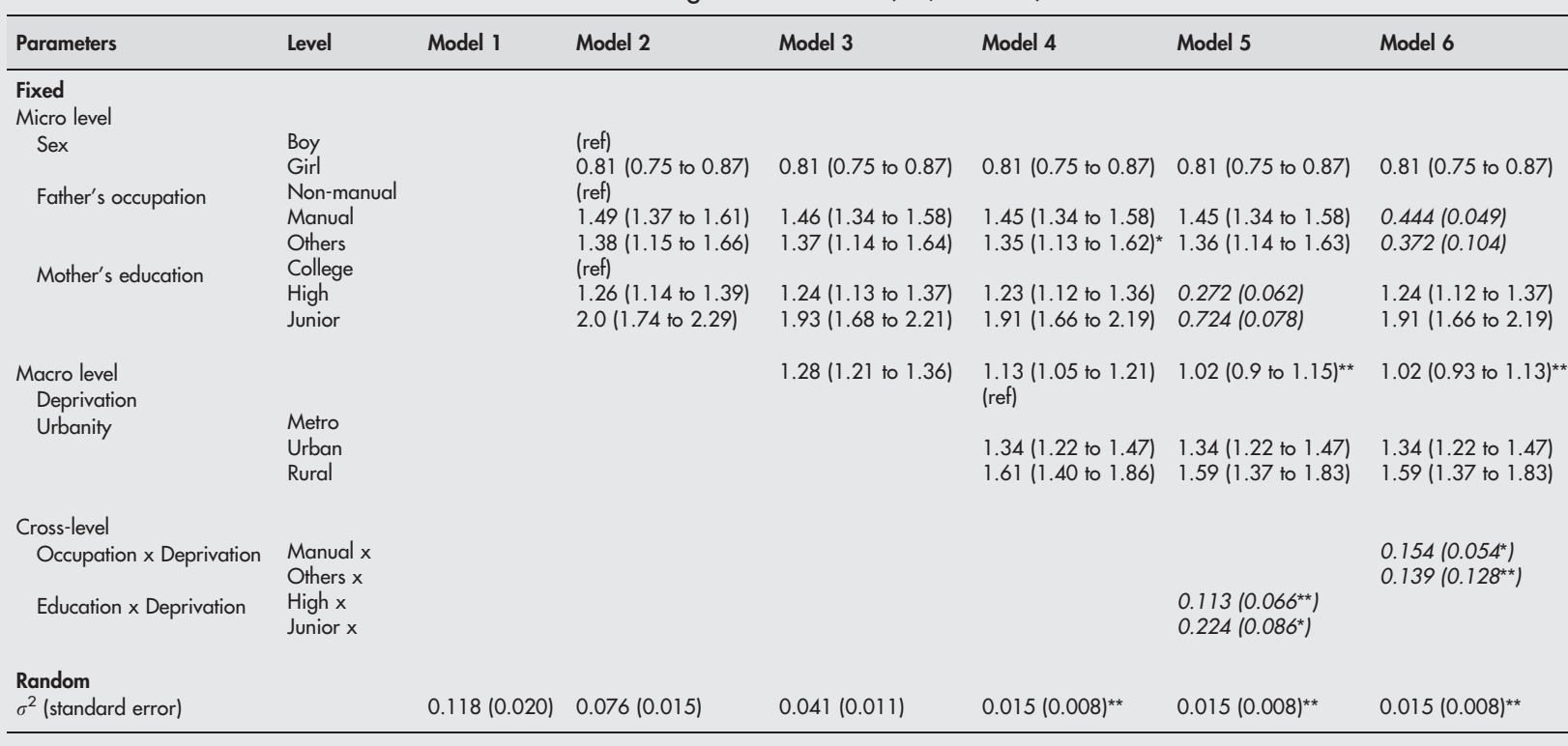

The estimates in italic are not RRs with confidence intervals, but coefficients with standard errors

All coefficients are statistically significant $(p<0.001)$ except for the cases marked $*(p<0.01)$ and ${ }^{* *}(p>0.05)$. 


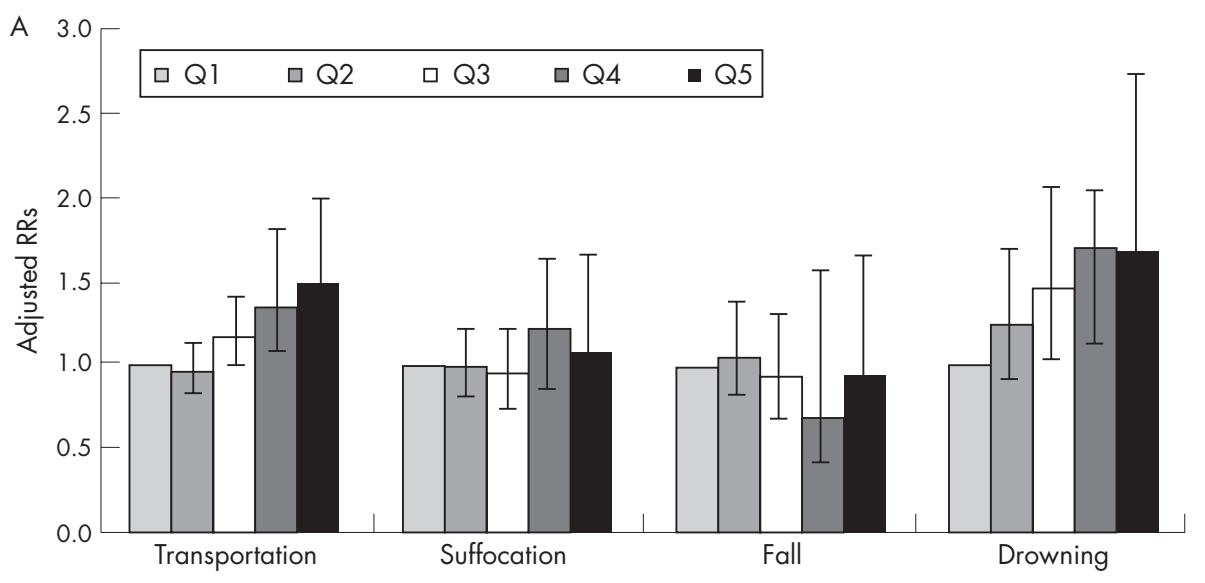

Figure 2 Area differentials in common types of injury by $(A)$ district deprivation level, and (B) the degree of urbanity. Relative risks and $95 \%$ confidence intervals were estimated from multilevel Poisson regression models, controlling for individual-level variables.

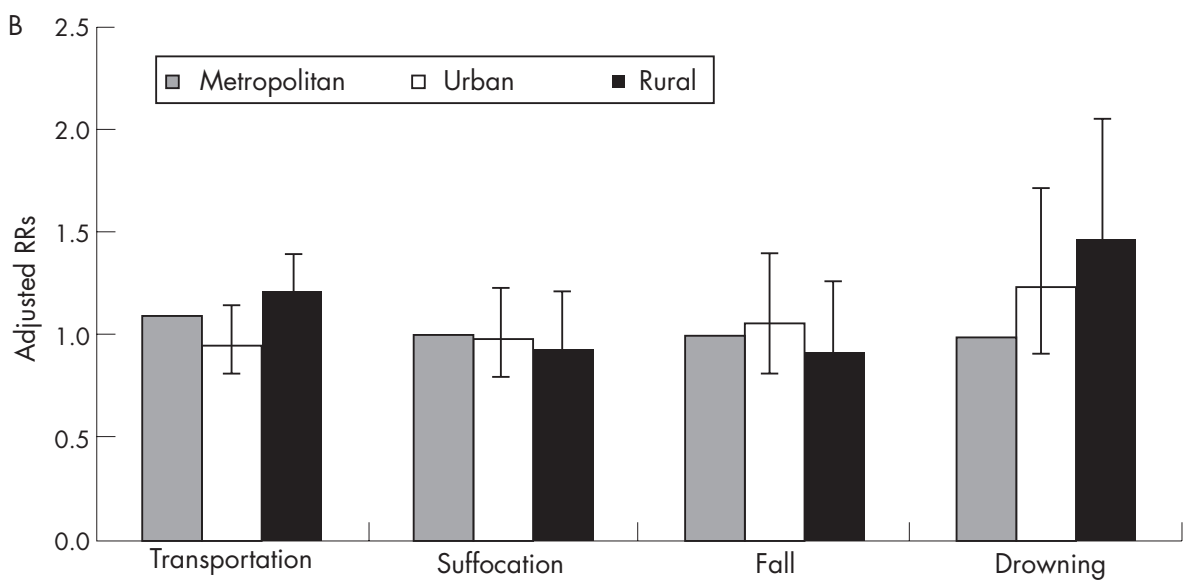

\section{Public health implications}

We found that boys had a higher risk for fatal injuries across all subgroups (tables 1-3), which was consistent with previous studies. ${ }^{6-10}$

Children born from lower social groups, such as fathers in manual occupations or mothers with less education, had higher risk than the others, regardless of their sex (tables 2 and 3). This could be explained by lack of supervision, poor housing environment (eg, steep stairway and old building) or inadequate access to information and preventive behaviour. ${ }^{3}{ }^{32}$ That is, obtaining quality information about child safety, sparing time and efforts for supervision, and living in a safer house is constrained by socioeconomic circumstances. In this regard, universally applicable social measures regardless of socioeconomic resources of individual households, such as legislation, enforcement of product standard or financial outlay, seem desirable rather than educating high-risk groups. ${ }^{33}$

As for area effects, living in non-metropolitan regions (especially rural) or more deprived districts was independently associated with increased risk for fatal childhood injuries, even after controlling for individual-level SEP. A previous multilevel study of area variation in childhood injury rates in the UK found that family factors could explain most of the area-level variation. ${ }^{31}$ The difference between that study and our findings could be attributable to: (1) the smaller spatial units (wards) examined in the British study; (2) the control for measures of family safety practices (in addition to socioeconomic factors) in the British study; and (3) the fact that the study areas in the British study included only deprived wards within one region, so that there was insufficient variation in socioeconomic conditions between the wards. We identified that a portion of variation across the districts came from different population compositions (models 1 and 2). However, the greater portion of variation was explained by deprivation and degree of urbanity (models 3 and 4). In addition, as the administrative designation of "rural/urban/metropolitan" on districts was based on their population size and share of primary industries (eg, agriculture and fishing) in their local economies, rural districts were likely to show more variability in mortalities due to small population size and to be more deprived (fig 1). However, these contextual variables were significant after simultaneous control for each other, suggesting that one trait could not be substituted with the other.

This contextual effect might come from a series of factors, ranging from the general resources and investment level of the places to the specific hazards or institutions relevant to injuries, including (1) environmental hazards such as dangerous streets or unprotected industrial and building sites; ${ }^{68}(2)$ municipal goods and services such as police, parks and healthcare facilities; ${ }^{20} 34$ (3) specific safety policies; ${ }^{9}$ or (4) socially and culturally determined attitudes or practice..$^{35}$ Looking at area differences according to types of injury, transportation and drowning showed a clear gradient across deprivation, which might be mediated by unprotected exposure to traffic and lack of safe playgrounds in more deprived districts. ${ }^{6-8} 102021$ On the other hand, non-metropolitan residence was associated with higher risk for most types of injury even at the same level of deprivation. ${ }^{1617} 19$ Especially, injuries by drowning, falls, and transportation showed the largest gaps, which may be related to the physical environment unique to rural areas (eg, neglected water reservoirs), ${ }^{517}$ unsafe housing conditions (eg, lack of window guards $)^{710}$ or insufficient neighbourhood resources (eg, lack of safe playgrounds). ${ }^{5}$ 


\section{What is already known}

- Many studies have reported that childhood injury, like other health problems, is more common among socioeconomically disadvantaged groups.

- However, until now, the effects of individual-level and area-level SEP have not been examined simultaneously, and evidence from non-Western societies is lacking.

\section{What this paper adds}

- Both individual-level and area-level SEP influenced the risk for fatal childhood injuries, and the area differentials were persistent across common types of injury.

- Injury prevention efforts should be directed towards both disadvantaged households as well as areas.

In addition, when examining cross-level interactions, synergistic effects were observed (models 5 and 6); children born from fathers in lower occupational class or mothers with less education and living in more deprived districts had an even higher risk for fatal injuries than those who were placed in only one group. Special attention should be paid to these groups in monitoring and implementing social interventions.

How can these inequalities in fatal childhood injuries be ameliorated? Some studies advocate targeted interventions for specific types of injury or vulnerable groups. ${ }^{80} 303637$ Other studies emphasise universal strategies to improve the general safety level and societal measures to remedy the underlying structure of social inequalities. ${ }^{36} 173338$ Our findings support the second view; in Korea, the absolute risk for childhood injury is higher compared with other developed countries, ${ }^{11}$ and we found that most types of injury occur more commonly in lower social groups at individual and area levels.

To reduce the gap between social groups as well as the absolute risk, universal strategies including safety regulation and balanced regional development should receive priority, and special efforts in implementation should be directed towards both disadvantaged households as well as areas. In addition, societal measures to mitigate underlying socioeconomic inequalities are required.

\section{Authors' affiliations}

M-H Kim, Department of Preventive Medicine, Eulji University School of Medicine, Daejeon, South Korea

S V Subramanian, I Kawachi, Department of Society, Human Development, and Health, Harvard School of Public Health, Boston, Massachusetts, USA

C-Y Kim, Seoul National University School of Public Health, Seoul, South Korea

Competing interests: None declared.

M-H K and C-Y K were recipients of the 2004-2005 David E Bell Fellowship program at the Harvard Center for Population and Development Studies, and Takemi Fellowship program at the Harvard School of Public Health, respectively. A substantial part of this paper was written during their fellowship.

\section{REFERENCES}

1 Peden M, McGee K, Krug E, eds. Injury: a leading cause of the global burden of disease, 2000. Geneva: World Health Organization, 2002.

2 Petridou E. Childhood injuries in the European Union: can epidemiology contribute to their control? Acta Paediatr 2000;89:1244-9.
3 Roberts I, Power C. Does the decline in child injury mortality vary by social class? A comparison of class specific mortality in 1981 and 1991. BMJ 1996;313:784-6

4 Singh GK, Yu SM. US childhood mortality, 1950 through 1993: trends and socioeconomic diffferentials. Am J Public Health 1996;86:505-12.

5 Cubbin C, Smith GS. Socioeconomic inequalities in injury: critical issues in design and analysis. Annu Rev Public Health 2002;23:349-75.

6 Haynes R, Reading R, Gale S. Household and neighbourhood risks for injury to 5-14 year old children. Soc Sci Med 2003;57:625-36.

7 O'Campo P, Rao RP, Gielen AC, et al. Injury-producing events among children in low-income communities: the role of community characteristics. J Urban Health 2000;77:34-49.

8 Reading R, Langford IH, Haynes R, et al. Accidents to preschool children: comparing family and neighbourhood risk factors. Soc Sci Med 1999:48:321-30

9 Sellstrom E, Guldbrandsson K, Bremberg S, et al. Association between childhood community safety interventions and hospital injury records: a multilevel study. J Epidemiol Community Health 2003;57:724-9.

10 Shenassa ED, Stubbendick A, Brown MJ. Social disparities in housing and related pediatric injury: a multilevel study. Am J Public Health 2004;94:633-9.

11 Unicef. A league table of child deaths by injury in rich nations. Florence: Unicef Innocenti Research Centre, 2001

12 Jo M-W, Khang Y-H, Yun S, et al. Proportion of death certificates issued by physicians and associated factors in Korea, 1990-2002. Korean J Prev Med 2004;37:345-52.

13 National Center for Health Statistics. ICD-10 framework: external cause of injury mortality matrix. Hyattsville, MD: National Center for Health Statistics, 2002.

14 Scholer SJ, Hickson GB, Ray WA. Sociodemographic factors identify US infants at high risk of injury mortality. Pediatrics 1999;103:1183-8.

15 Scholer SJ, Mitchel EF Jr, Ray WA. Predictors of injury mortality in early childhood. Pediatrics 1997; 100:342-7.

16 Baker SP, Whiffield RA, O'Neill B. County mapping of injury mortality. J Trauma 1988;28:741-5.

17 Brownell M, Friesen D, Mayer T. Childhood injury rates in Manitoba: socioeconomic influences. Can J Public Health 2002;93(Suppl 2):S50-6

18 Cubbin C, LeClere FB, Smith GS. Socioeconomic status and injury mortality: individual and neighbourhood determinants. J Epidemiol Community Health 2000;54:517-24.

19 Grossman DC, Kim A, Macdonald SC, et al. Urban-rural differences in prehospital care of major trauma. J Trauma 1997;42:723-9.

20 Hippisley-Cox J, Groom L, Kendrick D, et al. Cross sectional survey of socioeconomic variations in severity and mechanism of childhood injuries in Trent 1992-7. BMJ 2002;324:1132-7.

21 Laflamme L, Diderichsen F. Social differences in traffic injury risks in childhood and youth-a literature review and a research agenda. Inj Prev 2000;6:293-8.

22 Morris R, Carstairs V. Which deprivation? A comparison of selected deprivation indexes. J Public Health Med 1991;13:318-26.

23 Park N-H, Yeo E-G, Kim K-Y, et al. Improving income maintenance programs for the poor. Seoul: Korea Institute for Health and Social Affairs, 2003.

24 Fukuda Y, Nakamura K, Takano T. Municipal socioeconomic status and mortality in Japan: sex and age differences, and trends in 1973-1998. Soc Sci Med 2004;59:2435-45.

25 Subramanian SV, Chen JT, Rehkopf DH, et al. Racial disparities in context: a multilevel analysis of neighborhood variations in poverty and excess mortality among black populations in Massachusetts. Am J Public Health 2005;95:260-5.

26 Subramanian SV, Duncan C, Jones K. Multilevel perspectives on modeling census data. Environ Plann A 2001;33:399-417.

27 Snijders T, Bosker R. Multilevel analysis: an introduction to basic and advanced multilevel modeling. London: Sage, 2000.

28 Rasbash J, Steele F, Browne W, et al. A user's guide to MLwiN, version 2.0. London: Center for Multilevel Modelling, Institute of Education University of London, 2004.

29 Duncan C, Jones K, Moon G. Context, composition and heterogeneity: using multilevel models in health research. Soc Sci Med 1998;46:97-117.

30 Marcin JP, Schembri MS, He J, et al. A population-based analysis of socioeconomic status and insurance status and their relationship with pediatric trauma hospitalization and mortality rates. Am J Public Health 2003:93:461-6.

31 Kendrick D, Mulvaney C, Burton P, et al. Relationships between child, family and neighbourhood characteristics and childhood injury: a cohort study. Soc Sci Med 2005;61:1905-15

32 Rivara FP. Developmental and behavioral issues in childhood injury prevention. $J$ Dev Behav Pediatr 1995; 16:362-70.

33 Deen JL, Vos T, Huttly SR, et al. Injuries and noncommunicable diseases: emerging health problems of children in developing countries. Bull World Health Organ 1999;77:518-24.

34 Gofin R, Avitzour M, Haklai Z, et al. Injury inequalities: morbidity and mortality of 0-17 year olds in Israel. Int J Epidemiol 2002;31:593-9.

35 Soori H, Bhopal RS. Parental permission for children's independent outdoor activities. Implications for injury prevention. Eur J Public Health 2002;12:104-9.

36 Rivara FP. Prevention of injuries to children and adolescents. Inj Prev 2002;8(Suppl 4):IV5-8

37 Ekeus C, Christensson K, Hiern A. Unintentional and violent injuries among preschool children of teenage mothers in Sweden: a national cohort study. $J$ Epidemiol Community Health 2004;58:680-5.

38 Kendrick D, Marsh P. How useful are sociodemographic characteristics in identifying children at risk of unintentional injury? Public Health $2001 ; 115: 103-7$ 